MIDAS

Museus e estudos interdisciplinares

$7 \mid 2016$

Varia

\title{
Joana Baião - Museus, Arte e Património em Portugal: José de Figueiredo (1871-1937)
}

Duarte Manuel Freitas

\section{(2) OpenEdition}

Journals

Edição electrónica

URL: http://journals.openedition.org/midas/1050

DOI: $10.4000 /$ midas. 1050

ISSN: 2182-9543

Editora:

Alice Semedo, Paulo Simões Rodrigues, Pedro Casaleiro, Raquel Henriques da Silva, Ana Carvalho

Refêrencia eletrónica

Duarte Manuel Freitas, « Joana Baião - Museus, Arte e Património em Portugal: José de Figueiredo (1871-1937) », MIDAS [Online], 7 | 2016, posto online no dia 28 novembro 2016, consultado no dia 25 setembro 2020. URL : http://journals.openedition.org/midas/1050 ; DOI : https://doi.org/10.4000/ midas. 1050

Este documento foi criado de forma automática no dia 25 setembro 2020.

\section{c) (i)(2)}

Midas is licensed under a Creative Commons Attribution-NonCommercial-ShareAlike 3.0 International License 


\title{
Joana Baião - Museus, Arte e Património em Portugal: José de Figueiredo (1871-1937)
}

\author{
Duarte Manuel Freitas
}

\section{REFERÊNCIA}

Baião, Joana. 2015. Museus, Arte e Património em Portugal: José de Figueiredo (1871-1937).

Coleção Estudos de Museus. Casal de Cambra: Caleidoscópio e Direção-Geral de

Património Cultural. 439 páginas, ISBN: 978-989-658-344-6.

1 A presente obra de Joana Baião corresponde a uma adaptação da sua tese de doutoramento em História da Arte, especialidade em Museologia e Património Artístico, apresentada à Faculdade de Ciências Sociais e Humanas da Universidade Nova de Lisboa. O objeto de estudo recaiu sobre José de Figueiredo (JF), uma das personalidades mais singulares da historiografia artística e da Museologia portuguesa, cujo percurso profissional atravessou diferentes contextos políticos.

2 Logo no introitus, a autora estabelece como objetivo proceder a «um balanço crítico das ações e contribuições desta personalidade no panorama cultural português, bem como o seu enquadramento na cultura Europeia», almejando, igualmente, «entender como foi construído o "mito José de Figueiredo", uma personalidade que ainda hoje desperta ora admiração, ora antipatia, mas que dificilmente passa despercebida a quem estuda a história da arte, do património e da Museologia em Portugal» (p. 9). Destaque-se, em termos estruturais, a opção pelo seguimento de uma operatória específica da narrativa histórico-biográfica, em boa hora reabilitada pela historiografia mais recente e que a autora assume como o método mais eficaz para atingir os objetivos propostos, apresentando, na primeira parte, a descrição sumária do percurso do biografado e remetendo para a segunda parte uma análise pormenorizada das diversas áreas/ vertentes onde este se evidenciou. Tal opção revela-se acertada e coerente, permitindo 
ao leitor um seguimento claro dos conteúdos expostos, igualmente proporcionado pela escrita acessível (sem ser simplista) e direta da autora.

Os primeiros anos de vida de JF passaram-se na cidade do Porto onde nasceu, em 1871, no seio de uma família abastada de antigos emigrantes no Brasil. Coimbra deu-lhe uma formação universitária em Direito (1888-1893), embora não tenha sido da sua predileção, num contexto estudantil onde conheceu e privou, entre outros, com António Nobre, Eugénio de Castro, José Pinto Leite e Afonso Costa. A ida para Paris, onde permaneceu durante cinco anos (1895-1900), foi deveras fundamental para a sua formação nos "assuntos da arte", uma área em que, desde jovem, vinha demonstrando algum interesse. A fervilhante "cidade das luzes" finissecular apresenta-se como um palco ideal para a obtenção de competências no âmbito da Museologia e da história e crítica da arte, dada a presença de excelentes museus, antiquários, ateliers e centros de produção artística de diferentes disciplinas. Neste contexto, o biografado, para além da frequência de cursos livres dedicados à arte, privou com o cônsul Eça de Queirós, frequentou a atelier do escultor Rodin de quem foi amigo pessoal, estendendo igualmente a sua amizade a Salomom Reinach e a Yvanhoé Rambosson. Os conhecimentos adquiridos na estadia parisiense encontram-se expostos e desenvolvidos na publicação Portugal na Exposição de Paris (1901), uma espécie de resenha analítica da participação portuguesa no referido certame, ocorrido em 1900.

Ao ter entre mãos a difícil tarefa de traçar o percurso biográfico de JF, como se sucede na primeira parte da obra, é notória a escolha da autora pela explanação dos contextos onde se inseriu o objeto de estudo, sobretudo quando a informação recolhida não permitiu depreender uma ação ou atitude efetiva provinda por parte deste. A ausência ou escassez de fontes moldou a construção de um discurso historiográfico pleno de conjunturas e explicações das dinâmicas culturais, não se esquivando ao levantamento de suposições, ainda que geralmente fundamentadas.

5 Em 1901, JF regressa a Portugal e instala-se na cidade de Lisboa. Depressa consegue um emprego público e afirma-se, com relativa facilidade, nos meios artísticos e intelectuais da capital. Os seus serviços tornam-se requisitados, levando-o a integrar importantes órgãos de decisão sobre os assuntos ligados à arte. Ao reconhecimento da Monarquia Constitucional, juntou-se, mais tarde, o da I República, que, em 1911, o levou ao posto de diretor do Museu Nacional de Arte Antiga (MNAA). Segundo a observação pertinente de Joana Baião, «o não engajamento de José de Figueiredo a partidos políticos, aliado ao respeito e prestígio que foi granjeando por via do seu trabalho e dos ecos de reconhecimento que vinha do estrangeiro, terão sido o garante de uma passagem incólume pelas oscilações políticas de toda a $1 .^{\mathrm{a}}$ República e, depois, da sua perfeita integração nas conjunturas políticas que se lhe seguiram» (p. 75). Com efeito, durante a ascensão e os primeiros anos do Estado Novo, JF conseguiu manter intocável o seu prestígio, moldando-se facilmente às especificidades do regime, acrescendo ainda o facto de nutrir pelo Presidente do Conselho, António de Oliveira Salazar, uma especial admiração, manifestada publicamente e conforme se constata em privado, através das missivas trocadas entre ambos, que, inclusive, permitiram o desbloqueamento de alguns impasses.

6 Com o título «Uma Vida Dedicada à Arte Portuguesa (1901-1937)», a autora demarca a segunda parte do referido estudo, deixando cair a diretriz cronológica aplicada ao capítulo anterior e enveredando pela estruturação temática, com vista a proceder a uma análise exaustiva das diferentes áreas de intervenção de JF. Ganham particular 
destaque as ações empreendidas enquanto historiador e crítico de arte, como redator de diplomas legais e no papel que tomou à frente do MNAA.

7 Avaliar o peso de JF como historiador e crítico de arte remete-nos, indubitavelmente, para o estudo A Arte Portugueza Primitiva. O Pintor Nuno Gonçalves (1910), várias vezes citado (e não menos vezes seguido de modo acrítico) no âmbito dos ditos Painéis de São Vicente, sendo esta uma temática, ainda hoje, conflituosa e causadora de diversos atritos nos meandros da historiografia portuguesa. Além de propor uma datação e proveniência, de defender uma autoria (Nuno Gonçalves) e sugerir uma identificação das figuras retratadas, JF asseverou a existência de uma escola portuguesa de pintura "primitiva", "contaminado" o discurso historiográfico com laivos de um nacionalismo pungente, ainda assim consentâneo com o que se fazia em termos internacionais. Joana Baião não deixou de salientar as evidentes debilidades metodológicas do biografado, apresentando-as à luz das acesas discussões tidas com Joaquim de Vasconcelos e Vergílio Correia. Com este último, cuja animosidade é por demais evidente, JF secundariza a importância do documento histórico em história da arte, valorizando, sobretudo, a observação direta (aludida como "leitura da obra") enquanto método eficaz para extrair informações ditas coevas.

Enquanto participante ativo na produção legislativa dos assuntos do foro artístico, destaque-se a interferência da referida personalidade na elaboração da lei de 26 de maio de 1911, que reorganizou os serviços de arte e de arqueologia do país. Tais reformulações, enquadradas no espírito vigente da jovem República, almejaram, no âmbito da política patrimonial, uma evidente descentralização do poder, através da instituição de Conselhos de Arte e de Arqueologia com sede nas três principais cidades do país. As fontes elencadas por Joana Baião corroboram o papel ativo de JF na redação do referido diploma, que estabelece o nascimento da instituição museológica que dirigirá a partir de 1911, fruto da divisão do Museu Nacional de Belas Artes em dois organismos distintos: o MNAA e o Museu Nacional de Arte Contemporânea.

É precisamente na análise ao período de vigência de JF à frente do museu da Janelas Verdes que a obra atinge o ponto de maior valia. Atendendo ao seu papel de museólogo, Joana Baião ressalta, em jeito conclusivo, «o trabalho desenvolvido no Museu Nacional de Arte Antiga, instituição que organizou lentamente mas com eficácia, acompanhando dentro do possível as movimentações internacionais feitas nessa área, e que logrou transformar, indiscutivelmente, no "primeiro museu português", o modelo a seguir pelas restantes instituições museológicas do país» (p. 368). Dos parâmetros museológicos dissecados e que permitiram a autora chegar à conclusão acima citada, destacam-se a:

a) ampliação das instalações do museu, a partir da incorporação da igreja das Albertas e a construção de um edifício anexo;

b) remodelação dos espaços internos e aplicação de critérios de organização museográfica;

c) promoção da instituição museológica a partir de exposições temporárias e do empréstimo de peças a museus e exposições ocorridas no estrangeiro;

d) planificação e execução de um "serviço de extensão escolar", que embora devidamente identificado, não deteve, em termos analíticos, a devida atenção por parte da autora;

e) instalação de uma oficina de restauro anexa ao museu, dirigida por Luciano Freire; 
f) formação de conservadores (Vergílio Correia, Luís Keil e João Couto), cuja qualidade dos seus serviços beneficiou a instituição e, de certo modo, o próprio país, nas áreas da história da arte e da Museologia;

g) constituição de um grupo de amigos do museu, que serviu de apoio às aspirações da instituição.

10 A exaltação da memória tende, por vezes, à criação do mito, o que, com JF, não deixou de se suceder. Atendendo a tal evidência, e na tentativa de procurar o cerne no ser humano e não no que fizeram dele, é de enaltecer a total imparcialidade da autora que, mais do que articular e escalpelizar analiticamente uma série de dados, não deixou de expor a densidade psicológica de uma personalidade claramente ambiciosa e rica em contradições. Em suma: estamos perante uma investigação de fôlego, madura e de grande sentido crítico, afirmando-se, sobretudo, como obra basilar para o conhecimento da génese e evolução do primus inter pares dos museus portugueses.

\section{AUTORES}

\section{DUARTE MANUEL FREITAS}

Centro de História da Sociedade e da Cultura da Universidade de Coimbra, Portugal, duartemanuelfreitas@gmail.com 